\title{
Development of a multi-locus sequence typing system helps reveal the evolution of Cardinium hertigii, a reproductive manipulator symbiont of insects
}

\author{
Corinne M. Stouthamer ${ }^{1}$, Suzanne E. Kelly ${ }^{1}$, Evelyne Mann², Stephan Schmitz-Esser ${ }^{3}$ and Martha S. Hunter ${ }^{1 *}$ (D)
}

\begin{abstract}
Background: Cardinium is an intracellular bacterial symbiont in the phylum Bacteroidetes that is found in many different species of arthropods and some nematodes. This symbiont is known to be able to induce three reproductive manipulation phenotypes, including cytoplasmic incompatibility. Placing individual strains of Cardinium within a larger evolutionary context has been challenging because only two, relatively slowly evolving genes, $16 \mathrm{~S}$ rRNA gene and Gyrase B, have been used to generate phylogenetic trees, and consequently, the relationship of different strains has been elucidated in only its roughest form.
\end{abstract}

Results: We developed a Multi Locus Sequence Typing (MLST) system that provides researchers with three new genes in addition to Gyrase B for inferring phylogenies and delineating Cardinium strains. From our Cardinium phylogeny, we confirmed the presence of a new group D, a Cardinium clade that resides in the arachnid order harvestmen (Opiliones). Many Cardinium clades appear to display a high degree of host affinity, while some show evidence of host shifts to phylogenetically distant hosts, likely associated with ecological opportunity. Like the unrelated reproductive manipulator Wolbachia, the Cardinium phylogeny also shows no clear phylogenetic signal associated with particular reproductive manipulations.

Conclusions: The Cardinium phylogeny shows evidence of diversification within particular host lineages, and also of host shifts among trophic levels within parasitoid-host communities. Like Wolbachia, the relatedness of Cardinium strains does not necessarily predict their reproductive phenotypes. Lastly, the genetic tools proposed in this study may help future authors to characterize new strains and add to our understanding of Cardinium evolution.

Keywords: Endosymbiont, Wolbachia, Cytoplasmic incompatibility, Parthenogenesis induction, Feminization, MLST, Phylogenetics

\section{Background}

The life histories and evolution of many multicellular organisms are intimately entwined with the microbes they carry [1]. A large number of arthropods carry maternally inherited, intracellular bacterial symbionts that can affect their host's reproductive outcomes in both detrimental and beneficial ways $[2,3]$. These symbionts come from

\footnotetext{
* Correspondence: mhunter@email.arizona.edu; mhunter@ag.arizona.edu ${ }^{1}$ Department of Entomology, University of Arizona, 410 Forbes Building, Tucson, AZ 85721, USA

Full list of author information is available at the end of the article
}

various bacterial phyla, but are categorized based on their associations with their hosts. Primary (or obligate) symbionts complement their hosts' diet with essential amino acids or other limiting nutrients, are often housed in specialized structures, and are essential to their host's reproduction (reviewed in Moran et al [2]). Secondary (or facultative) symbionts, though largely unnecessary for successful host reproduction, can provide conditional benefits to their host, have no measurable effect, or manipulate their host's reproduction in ways that increase the spread of the symbiont [4-6].

(c) The Author(s). 2019 Open Access This article is distributed under the terms of the Creative Commons Attribution 4.0 International License (http://creativecommons.org/licenses/by/4.0/), which permits unrestricted use, distribution, and reproduction in any medium, provided you give appropriate credit to the original author(s) and the source, provide a link to the Creative Commons license, and indicate if changes were made. The Creative Commons Public Domain Dedication waiver (http://creativecommons.org/publicdomain/zero/1.0/) applies to the data made available in this article, unless otherwise stated. 
Symbiont phylogenies may offer clues to the relationship between the symbionts and their hosts. For instance, primary symbionts, such as Buchnera in their aphid hosts, display congruent phylogenies [7], indicating the long evolutionary history and cospeciation of these groups. Secondary symbionts generally have shorter associations with their hosts and may occur at intermediate frequencies within the host population [2]. The evolutionary phylogenies of secondary symbionts generally display many host switches and are noncongruent with their host's phylogenies (e.g. [8]). Genera of bacteria commonly thought of as secondary symbionts may also include lineages of primary symbionts in their midst, as with Serratia symbiotica in aphids $[9,10]$. Even the best-known secondary symbiont, Wolbachia, a notorious host switcher, contains a clade of symbionts that display congruent evolution and co-cladogensis in their obligatory symbiosis with nematodes $[11,12]$ as well as a lineage that is required for B-vitamin production in bedbugs [13]. These patterns show that different strains within one group of secondary symbionts can differ dramatically in their relationships with their hosts.

While transitions from secondary to obligate symbiosis may be apparent in phylogenies, as shown by host and symbiont phylogenetic congruence, subtler facets of secondary symbiont life histories may also be elucidated by a well-resolved phylogeny. Horizontal transmission of secondary symbionts between hosts is key to the secondary symbiont lifestyle, yet these transmission events are rarely captured in experiments (see exceptions in Huigens et al. [14] and Caspi-Fluger et al. [15]), and are likely to happen infrequently in nature. Phylogenies are currently the most powerful tools we have to describe these host switches. Well resolved phylogenies may also elucidate co-cladogenesis over a short evolutionary time scale, which can occur when a reproductive manipulator in essence "hijacks" a key reproductive function of their host, creating host-symbiont dependency $[6,16,17]$. In this paper, we explore evolution of the secondary symbiont of arthropods, Cardinium hertigii (Bacteroidetes), and address questions concerning horizontal transmission and the evolution of reproductive manipulations with a well-resolved phylogeny.

Cardinium hertigii, a member of the phylum Bacteroidetes, infects approximately 7-9\% of arthropods [18-20] as well as at least one lineage of the plant parasitic nematode, Heterodera glycines [21, 22]. Although it infects many insects, particularly members of Hymenoptera and Hemiptera, much of the diversity of this symbiont genus as described so far appears to lie in arachnids, such as mites, spiders, and harvestmen as hosts [18, 23, 24]. Although the phenotype of Cardinium in many hosts is unknown, it has been shown to manipulate host reproduction in insects and mites, and rivals Wolbachia in its versatility. Strains of Cardinium induce at least three reproductive manipulations: parthenogenesis, feminization, and cytoplasmic incompatibility $(\mathrm{CI})$.

In symbiont-induced parthenogenesis, genetic males turn into genetic females during embryogenesis. Parthenogenesis has been shown or associated with Cardinium infection in several parasitoid wasps in the genus Encarsia [20, 25] and with the oleander scale, Aspidiotus nerii [26]. In feminization, as has been shown in Brevipalpus mites, Cardinium causes infected genetic males to be converted into functional females [27]. Finally, Cardinium is able to induce cytoplasmic incompatibility in several wasps, mites, planthoppers and a thrips [2835 , where infected females produce both male and female offspring, but uninfected females mated with infected males produce few or no offspring (in diploid systems) or few or no daughters (in haplodiploid systems). Of all reproductive manipulators, so far only Cardinium, Wolbachia, and a recently discovered Alphaproteobacterium [36] have been found to induce $\mathrm{CI}$, although genomic evidence of the Cardinium strain cEper1, found in the parasitic wasp Encarsia suzannae, suggest that at least Wolbachia and Cardinium independently evolved this trait [37]. In addition to the reproductive manipulations, Cardinium has been shown to affect other host fitness traits as well. In the planthopper Sogatella furcifera, Cardinium infection is associated with faster nymphal developmental times [34] and in the parasitoid wasp Encarsia inaron, Cardinium infection is associated with increased longevity of female wasps [38].

Despite the diverse impacts Cardinium can have on key aspects of its host's survival and reproduction, few resources have been devoted towards developing better genetic tools for assessing the evolutionary history of this genus, leaving open some intriguing questions about the symbiont's evolution and ecological interactions with its hosts. Some of the enduring mysteries involving secondary symbionts, and Cardinium in particular, are how these reproductive manipulations evolved. For example, are the genes coding for these manipulations largely horizontally transmitted between strains or do they evolve independently, perhaps repeatedly, within lineages? Additionally, Cardinium horizontal transmission rate at a genus-wide level is poorly understood. With weakly resolved phylogenies, it is not clear whether Cardinium displays the same low level of host affinity as most other secondary symbionts, or whether the shorter list of host taxa with which it is associated than, for example, the cosmopolitan Wolbachia, is indicative of fewer host switches among host lineages. While a total of six Cardinium genomes have now been sequenced [39-44] genetic resources that enable broad comparisons among many taxa are still needed. We present four 
sets of primers from single locus housekeeping genes that each amplify $450-700 \mathrm{bp}$ of DNA in order to more fully resolve the evolutionary relationships of the divergent Cardinium strains. By providing primers for the community of Cardinium researchers to use to diagnose Cardinium and discriminate among as yet uncharacterized strains, the study provides a framework for future studies of this versatile symbiont.

\section{Results}

MLST primers

Most of the arthropod Cardinium in our set of host taxa (Table 1) could be amplified by the MLST primers (Table 2), including members from groups A (the largest arthropod group), $\mathrm{C}$ (biting midges in the Culicoides group), and D (Opiliones group). All primers amplified products for Cardinium residing in Opiliones and Culicoides spp. The EF-G primers worked on all samples, the $\operatorname{SufB}$ and $G y r B$ primers worked on most samples in group $A$ and all in group $C$ and $E$. For the GroEL primers, two sets of forwards were used (Table 2), depending on which amplified better, but only sequences from the inner forward primer (groel_346F) were used for the phylogenies.

\section{Phylogenetic trees}

The phylogeny of concatenated MLST loci supports the monophyly of Cardinium as a genus (Figs. 1 and 2). While the individual gene trees are not completely topologically congruent (Figs. 3, 4, 5, and 6), all phylogenies suggest that groups $\mathrm{A}$ and $\mathrm{C}$ are each supported as monophyletic groups, as proposed by Nakamura et al. [24]. In addition, the suggestion that group E, with hosts in the Opiliones, is a separate clade [23] is also supported by both individual gene trees as well as the concatenated tree. Evidence of host affinity of related Cardinium strains is also shown across phylogenies. This is shown particularly in group A in the Cebaeus spider clade, and in a smaller clade showing the sister relationship between strains in the two mites, E. suginamensis and T. pueraricola. Further, group $C$ is now populated entirely by Culicoides hosts, and group $\mathrm{E}$ contains entirely Opiliones hosts.

\section{Discussion}

This study aimed to better understand the evolution of the diverse arthropod symbiont Cardinium, and provide genetic tools to better identify individual strains within this group. Phylogenies based on sequences derived from four loci across a representative set of Cardinium strains show a greater resolution of Cardinium clades in this diverse genus than single gene trees using more slowly evolving DNA such as the 16S rRNA gene.
Direct sequencing and analysis of the genes selected for the MLST and phylogenetic analyses suggested that they were almost always single copy genes, although there appeared to be two copies of SufB in one host species, the planthopper Sogatella furcifera. The single gene trees were not entirely congruent with each other (Figs. $3,4,5$, and 6), as is most common in bacterial multilocus sequence analyses [45], and underscores the value of combining data from multiple genes. There are several potential reasons for non-congruence of gene trees and lineage trees [46]. They include lateral gene transfer, which is common in bacterial endosymbionts. However, none of the MLST genes are among the 68 Cardinium genes that showed evidence of horizontal transfer in the Cardinium genome $c$ Eper1 [37]. Lineage sorting, where polymorphisms in a gene precede the lineage split is another possible cause of non-congruence, although lineage sorting is more likely when population sizes are large [46], and endosymbionts typically have small effective population sizes [2]. Lastly, gene duplication and extinction is another process that can lead to noncongruence of gene trees with lineage trees, since different loci may be represented in different terminal taxa, even in single copy genes [46].

Using $16 \mathrm{~S}$ rDNA and gyrase B, Nakamura et al. [24] grouped Cardinium into three groups: A, which contains Cardinium strains infecting insects, mites, and other arthropods, B, which contains the Cardinium strain infecting the plant parasitic nematode, Heterodera glycines; and $\mathrm{C}$, which contains Cardinium infecting biting midges in the genus Culicoides. These groups are supported in the current study using the concatenated sequence of four loci. Chang et al. [23] suggested that the Cardinium found in in the harvestmen clade (Leiobunum spp., Opiliones) might be an independent group, based on a phylogeny constructed using a partial $16 \mathrm{~S}$ rRNA sequence. However, because the 16S rRNA gene displays a relatively slow rate of evolution, the phylogeny provided limited support for this idea. The current phylogeny using the concatenated loci provides more robust support for a separate clade of Cardinium found in the Leiobunum Opiliones. Following the convention of Nakamura et al. [24] this clade is designated group E, with clade D reserved for Cardinium in Daphnia, water fleas [47].

The monophyly of Cardinium in the oleander scale, Aspidiotus nerii (Diaspididae), Encarsia parasitic wasps, and whiteflies is supported. Species of Encarsia that harbor these Cardinium parasitize either whiteflies (E. hispida, E. suzannae, E. tabacivora, E. inaron (IT and US)) or armored scale insects in the Diaspididae (E. perniciosi). The placement of these Encarsia Cardinium strains with those from scale insects $(A$. nerii) and whiteflies (A. floccosus, B. tabaci) suggests that horizontal 
Table 1 Collection localities of Cardinium strains and their associated reproductive phenotypes

\begin{tabular}{|c|c|c|c|}
\hline Host organism & $\begin{array}{l}\text { Cardinium } \\
\text { strain }\end{array}$ & Collection information & Reproductive phenotype \\
\hline Aleurothrixus floccosus & cAflo1 & Israel & Unknown \\
\hline Encarsia suzannae & cEper1 & Texas, USA & Cl (Hunter et al., 2003) \\
\hline Encarsia hispida & cEhis1 & San Diego, USA & PI (Zchori-Fein et al., 2004) \\
\hline Encarsia tabacivora & cEper2 & Brazil & PI association (Zchori-Fein et al., 2001) \\
\hline $\begin{array}{l}\text { Encarsia inaron (IT), high } \\
\text { density strain (HIT) }\end{array}$ & cEina2 & Italy & $\begin{array}{l}\text { One of two strains co-infecting a host with a Cl phenotype (Gebiola et al., 2016). } \\
\text { This strain does not cause Cl (Stouthamer, et al. unpubl.) }\end{array}$ \\
\hline $\begin{array}{l}\text { Encarsia inaron, (IT), low } \\
\text { density strain (LIT) }\end{array}$ & cEina3 & Italy & $\begin{array}{l}\text { One of two strains co-infecting a host with a Cl phenotype (Gebiola et al., 2016). } \\
\text { This strain causes Cl (Stouthamer et al. unpubl.) }\end{array}$ \\
\hline Encarsia inaron (USA) & cEina1 & USA & No Cl, no PI (White et al., 2009) \\
\hline Aspidiotus nerii & cAner1 & $\begin{array}{l}\text { University of California, } \\
\text { Riverside culture }\end{array}$ & Associated with parthenogenetic host (Provencher et al., 2005) \\
\hline $\begin{array}{l}\text { Bemisia tabaci, Q1 } \\
\text { species }\end{array}$ & cBtQ1 & Valencia, Spain & No Cl, no PI (Fang et al., 2014) \\
\hline Ixodes scapularis cell line & clscal & $\begin{array}{l}\text { Nantucket Island } \\
\text { (Massachusetts), USA }\end{array}$ & Unknown \\
\hline Indozuriel dantur & cldan1 & Japan & Unknown \\
\hline Sogatella furcifera & cSfur1 & China & Unknown \\
\hline Sogatella furcifera & cSfur2 & Japan & Cl (Nakamura et al., 2009) \\
\hline $\begin{array}{l}\text { Eotetranychus } \\
\text { suginamensis }\end{array}$ & cEsug1 & Taiwan & Cl (Gotoh et al., 2007) \\
\hline Oligonychus coffeae & cOcof1 & Japan & Unknown \\
\hline Oligonychus gotohi & cOgot1 & Japan & Unknown \\
\hline Panonychus mori & cPmor1 & Japan & Cl (Gotoh et al., 2003) \\
\hline Tetranychus pueraricola & cTpue1 & Japan & No Cl, no PI (Gotoh et al., 2003) \\
\hline Culicoides arakawae & cCara1 & $\begin{array}{l}\text { Kagoshima Pref. or } \\
\text { Okinawa Pref., Japan }\end{array}$ & Unknown \\
\hline Culicoides ohmorii & cCohm1 & Kagoshima Pref, Japan & Unknown \\
\hline Culicoides peregrinus & cCper1 & $\begin{array}{l}\text { Yonaguni Isl., Okinawa } \\
\text { Pref. Japan }\end{array}$ & Unknown \\
\hline Culicoides punctatus & cCpun1 & $\begin{array}{l}\text { Leahurst Campus, } \\
\text { University of Liverpool, UK }\end{array}$ & Unknown \\
\hline Cybaeus eutypus & cCeut & Vancouver Island, Canada & Unknown \\
\hline Cybaeus signifer & cCsig1 & Vancouver Island, Canada & Unknown \\
\hline Cybaeus chauliodus & cCcha1 & Northern California, USA & Unknown \\
\hline Cybaeus somesbar & cCsom 1 & Northern California, USA & Unknown \\
\hline Cybaeus sanbruno & cCsan1 & $\begin{array}{l}\text { North central California, } \\
\text { USA }\end{array}$ & Unknown \\
\hline Cybaeus morosus & cCmor1 & British Columbia, Canada & Unknown \\
\hline Cybaeus hesper & cChes1 & $\begin{array}{l}\text { North central California, } \\
\text { USA }\end{array}$ & Unknown \\
\hline Cybaeus multnoma & cCmul1 & Oregon, USA & Unknown \\
\hline Cybaeus penedentatus & ¿Cpen1 & $\begin{array}{l}\text { North central California, } \\
\text { USA }\end{array}$ & Unknown \\
\hline Culicoides imicola & cCimi1 & Unknown & Unknown \\
\hline Metaseiulus occidentalis & cMoccl & $\begin{array}{l}\text { Washington and Oregon, } \\
\text { USA }\end{array}$ & Cl (Roush and Hoy, 1981) \\
\hline Leiobunum sp 1 & CLsp2 & $\begin{array}{l}\text { Georgetown Island, } \\
\text { Maine, USA }\end{array}$ & Unknown \\
\hline
\end{tabular}


Table 1 Collection localities of Cardinium strains and their associated reproductive phenotypes (Continued)

\begin{tabular}{|c|c|c|c|}
\hline Host organism & $\begin{array}{l}\text { Cardinium } \\
\text { strain }\end{array}$ & Collection information & Reproductive phenotype \\
\hline Leiobunum sp 2 & CLsp3 & $\begin{array}{l}\text { N. Monmouth, Maine, } \\
\text { USA }\end{array}$ & Unknown \\
\hline Leiobunum & CLsp1 & $\begin{array}{l}\text { Ellison Park, Monroe } \\
\text { County, New York, USA }\end{array}$ & Unknown \\
\hline Brevipalpus californicus & cBcal1 & Minas Gerais, Brazil & Feminization (Groot and Breeuwer, 2006) \\
\hline Brevipalpus phoenicis & cBpho1 & Minas Gerais, Brazil & Feminization (Groot and Breeuwer, 2006) \\
\hline Macrosteles quadrilineatus & cMque1 & & Unknown \\
\hline Encarsia perniciosi & cEper3 & $\begin{array}{l}\text { Tijuana River Valley Park, } \\
\text { San Diego, USA }\end{array}$ & Associated with parthenogenetic host (Stouthamer and Luck, 1991) \\
\hline Pezothrips kellyanus & cPkel1 & Australia & $\mathrm{Cl}$ (Nguyen et al., 2017) \\
\hline
\end{tabular}



Fig. 1 Bayesian phylogeny with of all Cardinium strains from this study using concatenated loci: gyrB, sufB, EF-G, and groEL. Node support of > 0.99 posterior probability is indicated by an asterisk. Cardinium strains are labeled by the host taxon species name and colored by the host taxon order or sub-class. Acari are pink, Diptera are mustard yellow, Opiliones are green, Thysanoptera are grey, Hemiptera are light blue, Hymenoptera are orange, and Araneae are deep blue. Symbols refer to reproductive phenotype when it has been investigated: filled squares indicate cytoplasmic incompatibility (CI) has been shown, empty squares indicate $\mathrm{Cl}$ has been looked for and not found, filled triangles indicate feminization, filled circles indicate parthenogenesis-induction has been shown, and hatched circles indicate an association with a parthenogenetic host 


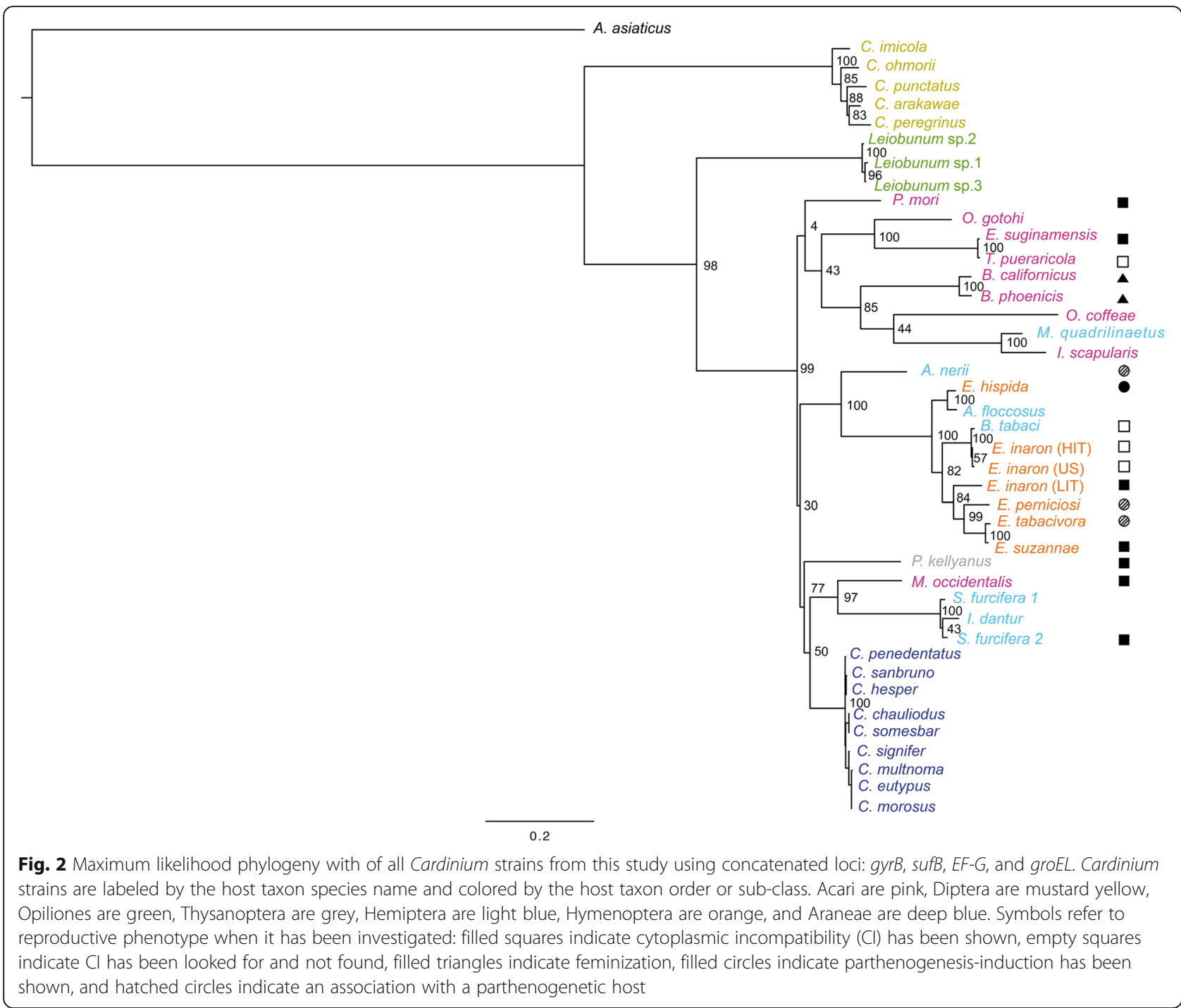

transmission events between host and parasitoids, and perhaps among parasitoids, have occurred, although the directionality of these events can only be discerned with a deeper sampling of both hosts and parasitoids. Additionally, none of the closely related strains of Cardinium residing in whiteflies, and two related species of Encarsia (cBtQ1, $c$ Eina1, $c$ Eina2) are known not to cause CI or any other reproductive manipulations $[48,49]$. This suggests that the ancestral strain of Cardinium in this group either spread with a phenotype other than some type of reproductive manipulation, or lost its ability to manipulate in each new host after it spread. The Cardinium group in this clade is the clearest example of closely related Cardinium strains residing in distantly related hosts, in contrast to the previously observed pattern of closely related Cardinium strains residing in closely related hosts [24, 50-52], a pattern which is generally supported in the phylogenies of the current study as well.
Interestingly, some patterns appear at least superficially similar between Cardinium and Wolbachia. The reproductive manipulations that Cardinium is able to induce overlap with Wolbachia. Strains that cause the same reproductive manipulations do not clearly form one monophyletic clade, except perhaps in the case of the mite strains causing feminization, but this might change when further examples of feminizing Cardinium are discovered. Additionally, closely related Cardinium strains do not necessarily cause the same reproductive manipulations, as exemplified by the sister strains $c$ Eper1, which causes $\mathrm{CI}$, and the parthenogenesisinducing (PI) strain, $c$ Eper2 $[25,30]$. Similarly, $c$ Esug1, which causes $\mathrm{CI}$, and $c$ Tpue1, which does not cause CI or PI, are sister taxa [29]. This pattern also occurs in Wolbachia; closely related Wolbachia strains in Acraea butterflies have shown multiple transitions between sex ratio distorting and CI-inducing Wolbachia strains [53]. 




Fig. 3 Bayesian single gene tree of 482 bp of Translation Elongation Factor G (EF-G) of all strains in this study. Asterisks indicate $>0.99$ posterior probability. Cardinium strains are labeled by the host taxon species name and colored by the host taxon order or sub-class. Acari are pink, Diptera are mustard yellow, Opiliones are green, Thysanoptera are grey, Hemiptera are light blue, Hymenoptera are orange, and Araneae are deep blue

Additionally, in Drosophila, wMel, causing CI, and wAu, having no phenotype, are also very closely related [54]. These similar patterns between Wolbachia and Cardinium trees are not necessarily expected; recently, it has been suggested that the horizontal transfer of the CI phenotype may be linked to the Wolbachia's WO phage, which can cross-infect Wolbachia strains $[55,56]$. So far, sequenced genomes of Cardinium do not show the presence of phage DNA. Unlike Wolbachia, however, many Cardinium strains do harbor plasmids [37, 40], which may serve a similar function in horizontal transmission of reproductive manipulation genes [57, 58].

We fully expect the phylogeny of Cardinium to become better resolved when more Cardinium genomes are published, as have Wolbachia genomes [59]. There are currently six Cardinium genomes published [37, 4044], three of them published in the last couple of years, so it is reasonable to expect more in the near future. Indeed, the high genetic diversity within this genus made the design of a single MLST, a scheme designed for strains within a bacterial species [60], challenging. However, while full genomes are always going to be better for inferring phylogenies and group placements [61], the cost of sequencing, the sequencing depth necessary for symbionts that may exist at relatively low titer in their hosts, and the expertise in assembling symbiont genomes from metagenome data can still be a limiting factor for many laboratories. For ecological studies and surveys in particular, the ability to relatively quickly type Cardinium strains meets the objective of giving the strain an identity and fitting it into the Cardinium phylogeny. This MLST offers a relatively low-cost way to differentiate between strains of Cardinium and is a starting point for researchers considering the study of Cardinium. In particular, the utility of the Cardinium MLST will be valuable in answering questions concerning relatively recent biogeographic or host switching events.

Characterizing a strain of a symbiont with an MLST allelic profile may be difficult when more than one strain 


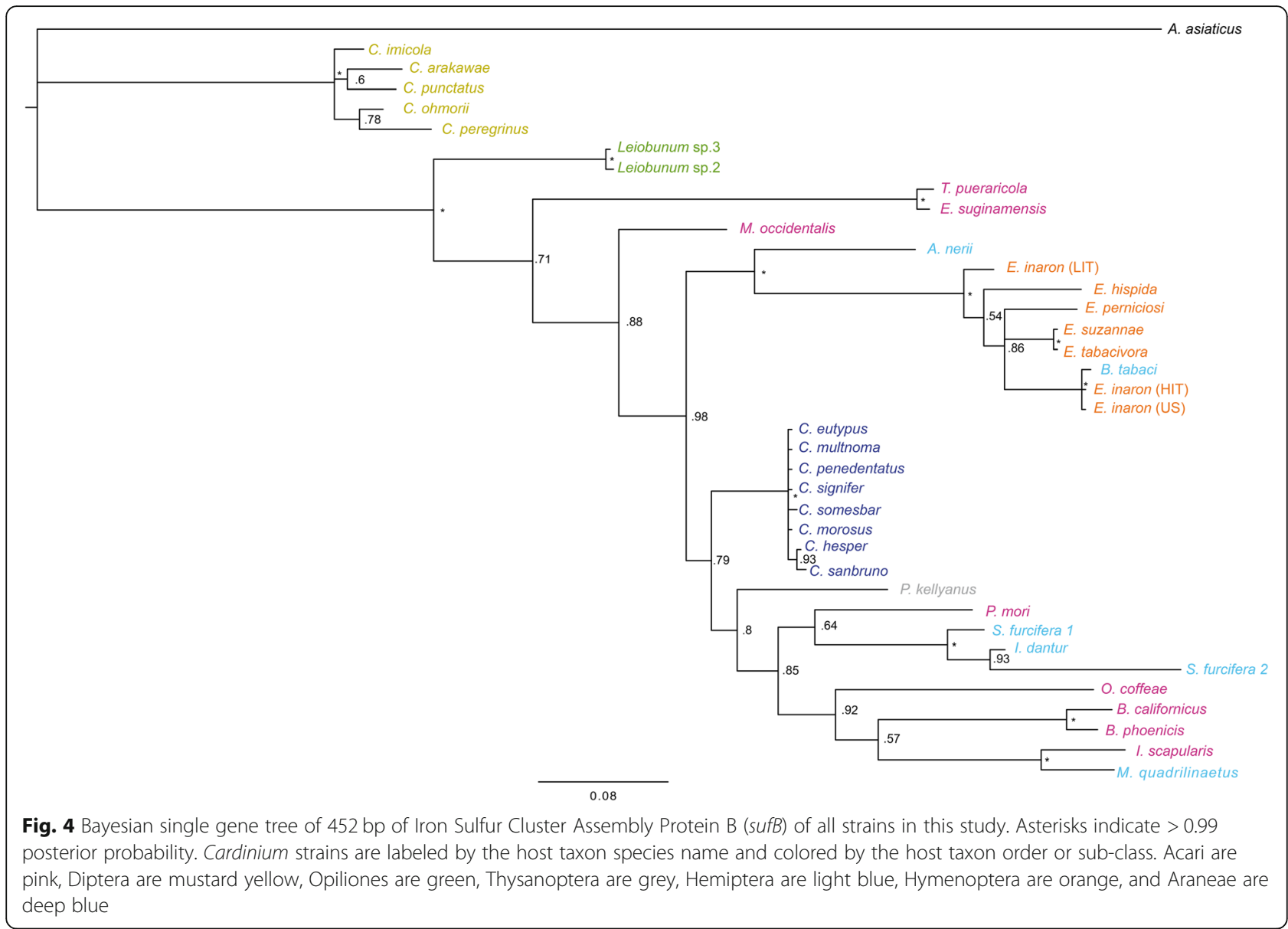

co-infects individual host individuals. If both alleles are amplified, direct sequencing may not be possible, and cloning may be required prior to sequencing. Even more challenging is determining which sequenced allele at a particular locus belongs to which strain. There are a couple of potential solutions to this problem. When multiple strains are present in different combinations among individuals, one can logically examine the sets of alleles in multiply infected and singly infected individuals to allow assignment of allelic profiles to strains, a system known as Allelic Intersection Analysis [62]. This may be particularly relevant in complex situations like that found in the apple maggot, Rhagoletis pomonella, where up to four Wolbachia strains have been found in multiple combinations [63]. Another tool that could be useful when co-infecting symbiont strains are found at different titers is quantitative PCR. It may be possible to design specific qPCR primers for each allele and quantify the relative titer of each. If the titer is consistently higher in one set of alleles than the other, one can presume the alleles in that set belong to the same strain. In the host Encarsia inaron (from Italy) coinfecting strains $c$ Eina2 and $c$ Eina 3 are found at high and low titers, respectively (Table 1).

\section{Conclusion}

Cardinium evolution appears to be driven by both ecological opportunity and host specialization. Cardinium has frequently switched between parasitoids and their hosts, even though they are physiologically quite different, causing these strains to form a clade. In contrast, the Cardinium in Cybaeus spiders, Culicoides spp., and Leobinium spp. appear to be quite specialized to particular host lineages, without distantly related hosts breaking up these clades. Similar to Wolbachia, the relatedness of Cardinium strains does not necessarily predict their reproductive phenotypes. Overall, the new genetic tools proposed in this study allow for clearer strain delimitation and a more detailed picture of the evolution of Cardinium, one that will keep unfolding the more the MLST primers are used to characterize strains and add taxa to the Cardinium phylogeny.

\section{Methods}

Gene selection

Four genes with the highest amino acid identity between the sister group to Cardinium, Amoebophilus asiaticus, and the sequenced Cardinium strain, $c$ Eper1, were chosen to develop a Multi Locus Sequence Typing 


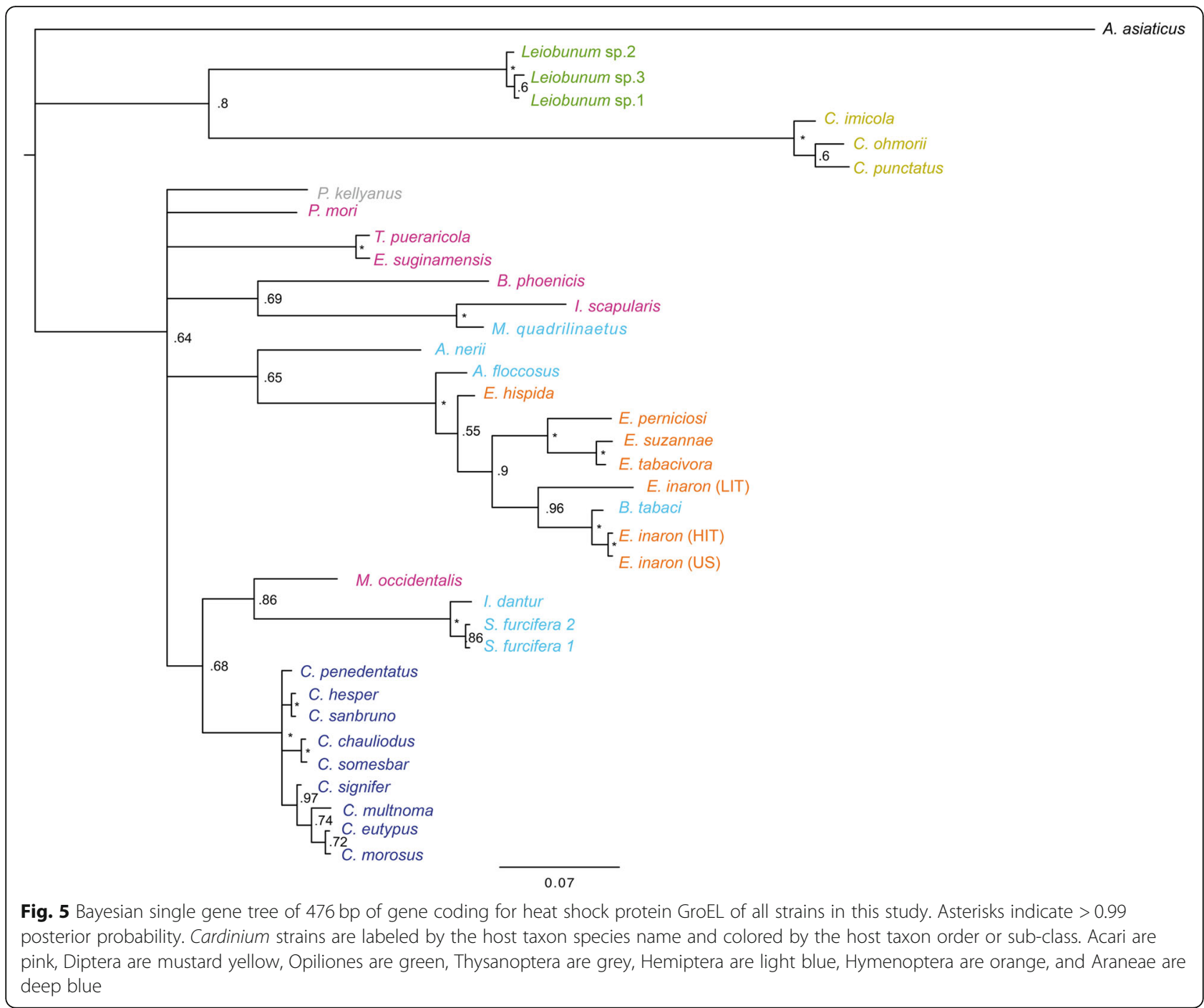

(MLST) system with other strains [37]. We did not attempt to choose genes that are evenly spaced around the Cardinium chromosome. While, in more conserved lineages, linkage among loci is often avoided by choosing MLST genes that are evenly spaced [60], in Cardinium there is little shared synteny, even between the two related sequenced genomes, $c \mathrm{BtQ} 1$ and $c$ Eper1 [40]. In addition to making even spacing of chosen genes unworkable across the genus, the low level of synteny suggests frequent gene rearrangements in this lineage, and a low probability of linkage among loci. The genes selected for this study were: Elongation Factor G, a protein responsible for coordinating the movement of tRNA and mRNA during translation [64]; gyrase $\mathrm{B}$, a topoisomerase that unwinds DNA during DNA replication [65]; Iron Sulfur Cluster Assembly Protein (SufB), a protein involved in generating Fe-S complexes mainly involved in electron transfer [66] and the Heat shock protein GroEL, a chaperone protein essential in stress-related responses [67].

\section{DNA extractions}

Arthropods with confirmed Cardinium infections and DNA samples were received from cooperators around the world (Table 1). From Japan (H. Noda), we received planthopper, mite, and biting midge DNA, extracted as described in Nakamura et al. [24]. Cardinium from the Ixodes cell line ISE6 (T. Kurrti) was processed by shearing the cells and filtering them through a $1.5 \mu \mathrm{m}$ syringe, then extracting the lysate with $3 \mu \mathrm{l}$ of $20 \mathrm{mg} / \mathrm{ml}$ proteinase $\mathrm{K}$ and $50 \mu \mathrm{l}$ of water with $10 \% \mathrm{w} / \mathrm{v}$ chelex beads [49]. Cybeus spiders (S. Perlman) were extracted using Qiagen DNeasy extraction kits. All other samples of alcoholpreserved specimen were also extracted using the chelex extraction protocol.

\section{Primer design, $\mathrm{PCR}$, and sequencing}

Primers were iteratively designed as sequenced products from strains were added to sequence alignments. Initially, general primers were designed based on the only 


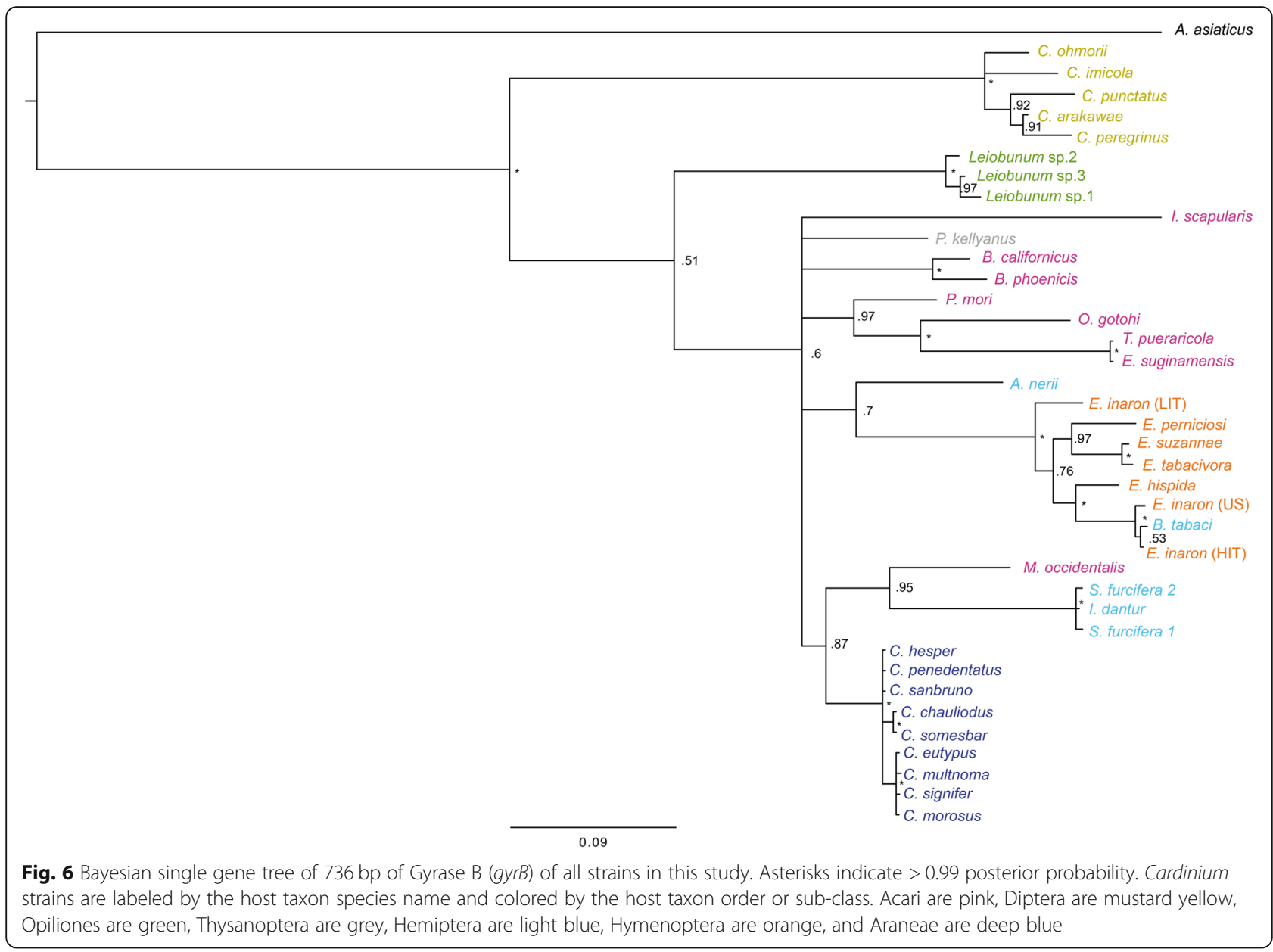

two sequenced (and closely related) Cardinium strains (cEper1, cBtQ1) and the sister taxon to Cardinium, Amoebophilus asiaticus 5a2. These initial primers were designed using $c$ Eper1 as the reference strand in Primer3 $[68,69]$ with ambiguities based on the other strains added manually. Amplification of some gene products was not successful from all strains using these initial primers, particularly from strains divergent with respect to $c$ Eper1 and $c \mathrm{BtQ} 1$, such as those in the biting midges, Culicoides spp. In these instances, strain-specific primers were designed once a small segment of the gene was sequenced. These strain-specific primers were then used in conjunction with the initial degenerate primers to obtain more sequence. When more than three bacterial strains were used for primer design, areas of conservation were manually detected and these potential primer

Table 2 MLST primers and their suggested melting temperatures for PCR

\begin{tabular}{|c|c|c|c|c|c|}
\hline Primer name & Primer sequence $\left(5^{\prime}-3^{\prime}\right)$ & $\operatorname{Tm}\left({ }^{\circ} \mathrm{C}\right)$ & Gene length (bp) & Amplified nucleotide range of gene (bp) & MLST fragment size (bp) \\
\hline gyrb_859F & ATGCAYGTMACBGGDTTTARAAG & 50 & 1950 & $859-1637$ & 736 \\
\hline gyrb_1637R & TARAGTGGRGGRGARGCAAT & & & & \\
\hline groel_346F & VTHAARCGBGGBATWGACAA & 52 & 1638 & $346-842$ & 476 \\
\hline groel_287Fa & CNCARKCTATWITYRYVCATGG & & & & \\
\hline groel_842R & TTGGBGAYAGAAGRAARGCNATG & & & & \\
\hline sufb_806F & CTACNGTDCARAATTGGTATCC & 50 & 1443 & $806-1289$ & 451 \\
\hline sufb_1289R & ADYTGRTCYKCRCTRATTIT & & & & \\
\hline EF_1689R & AAABCCYTTYTGAATIGCTGG & 52 & 2142 & $1689-1162$ & 482 \\
\hline EF_1162F & GCNGTRGTIGGITTTAARGARATTA & & & & \\
\hline
\end{tabular}

${ }^{\text {aAlternative forward primer for } \text { groEl }}$ 
regions were checked for hairpins and tendency to form primer dimers in Primer3 [69] against every strain. All primers were selected by minimizing the number of ambiguities and maximizing the number of conserved base pairs in the 3' primer region, and M13 tags were added to the primers for ease of sequencing [70].

Although the melting temperature varied depending on the primer pair (Table 1), PCR conditions were generally as follows: $15 \mu \mathrm{l}$ reaction volume with New England Biolabs buffer and Taq at $1 \mathrm{X}$ concentration, $5 \mathrm{mM}$ dNTPs, $0.76 \mathrm{mM} \mathrm{MgCl}_{2}, 1.1 \mu \mathrm{M}$ primers with $2 \mu \mathrm{l}$ of DNA. From mite extractions, $4 \mu \mathrm{l}$ of DNA was added (similar to Groot and Breeuwer (2006)). The initial melting temperature was $94{ }^{\circ} \mathrm{C}$ for $2 \mathrm{~min}$; this was followed by 40 cycles of $94^{\circ} \mathrm{C}$ for $45 \mathrm{~s}$, the annealing temperature (Table 1) for $45 \mathrm{~s}$, and extension at $68^{\circ} \mathrm{C}$ for $45 \mathrm{~s}$. The final extension was at $68^{\circ} \mathrm{C}$ for $7 \mathrm{~min}$.

\section{Phylogenetic analysis}

DNA sequences were quality-controlled and aligned using CLC Main Workbench 6 (Qiagen) and MUSCLE [71]. jModelTest was used to select the optimum model of evolution based on the Akaike information criterion [72]. Bayesian trees were constructed in MrBayes with one million Markov Chain Monte Carlo (MCMC) generations and sampled every 1000 generations [73]. Maximum likelihood trees were constructed using RaxML with 1000 rapid bootstraps. Both Bayesian and ML methods used the GTR + I + G model of nucleotide evolution with a total of 2145 bp from Gyrase B $(g y r B)$, translation elongation factor $\mathrm{G}(E F-G)$, Iron Sulfur cluster assembly protein (sufB), and heat shock protein (groEL) for each taxon, partitioned by gene and codon position. Phylogenetic tree figures were generated in Mesquite [74].

\section{Abbreviations}

Cl: Cytoplasmic incompatibility; MCMC: Markov chain Monte Carlo; MLST: Multi-locus sequence typing; PCR: Polymerase chain reaction; PI: Parthenogenesis-induction; qPCR: Quantitative polymerase chain reaction

\section{Acknowledgements}

We are very grateful to a number of people who sent us many Cardiniuminfected specimens: Tim Kurtii, Marjorie Hoy, Johannes Breeuwer, Hiroaki Noda, Steve Perlman, Jack Werren, Yuval Gottlieb, Nir Netanel, and Markus Riegler. We are also grateful to Wendy Moore, who provided comments on an earlier version of the MS and consulted on the phylogenetic analysis, as did James Robertson. Garrett Hughes also consulted on tree building.

\section{Authors' contributions}

CMS analyzed sequences, designed primers, performed the experiments and phylogenetic analyses and wrote the first draft of the manuscript. SEK assisted with PCR, helped develop and test methods, and revised drafts of the manuscript. EM consulted on experimental methods, made figures and revised drafts of the manuscript. SS-E consulted on experimental methods, served as a mentor in the design and performance of the research and revised drafts of the manuscript. MSH worked with CMS on the design and execution of the project and worked with CMS on the writing and revision of all drafts of the manuscript. All authors read and approved the final manuscript.

\section{Funding}

Funding for this study was provided by an NSF grant (IOS-1256905) to MSH and SSE, and by the center for Insect Science at the University of Arizona to CMS. Neither funding body had any role in the design of the study or collection, analysis, and interpretation of data or in writing the manuscript.

\section{Availability of data and materials}

The sequence datasets generated and/or analyzed during the current study have been deposited in the NCBI repository, under accession numbers MK264778-MK264911 [https://www.ncbi.nlm.nih.gov/nuccore/].

\section{Ethics approval and consent to participate \\ NA}

\section{Consent for publication}

NA

Competing interests

The authors declare that they have no competing interests.

\section{Author details}

${ }^{1}$ Department of Entomology, University of Arizona, 410 Forbes Building, Tucson, AZ 85721, USA. ${ }^{2}$ Milk Technology and Food Science, Institute for Milk Hygiene, University of Veterinary Medicine, Vienna, Austria. ${ }^{3}$ Department of Animal Science, lowa State University, Ames, lowa, USA.

Received: 17 January 2019 Accepted: 12 November 2019

Published online: 27 November 2019

\section{References}

1. McFall-Ngai M, Hadfield MG, Bosch TCG, Carey HV, Domazet-Loso T, Douglas $A E$, et al. Animals in a bacterial world, a new imperative for the life sciences. Proc Natl Acad Sci U S A. 2013;110(9):3229-36.

2. Moran NA, McCutcheon JP, Nakabachi A. Genomics and evolution of heritable bacterial symbionts. Annu Rev Genet. 2008;42:165-90.

3. O'Neill SL, Hoffmann AA, Werren JH, editors. Influential passengers. New York: Oxford University Press; 1997.

4. Stouthamer R, Breeuwer JAJ, Hurst GDD. Wolbachia pipientis: microbial manipulator of arthropod reproduction. Annu Rev Microbiol. 1999;53:71-102.

5. Werren JH. Biology of Wolbachia. Annu Rev Entomol. 1997;42:587-609.

6. Zug R, Hammerstein P. Bad guys turned nice? A critical assessment of Wolbachia mutualisms in arthropod hosts. Biol Rev. 2015;90(1):89-111.

7. Clark MA, Moran NA, Baumann P, Wernegreen JJ. Cospeciation between bacterial endosymbionts (Buchnera) and a recent radiation of aphids (Uroleucon) and pitfalls of testing for phylogenetic congruence. Evolution. 2000:54(2):517-25.

8. Novakova E, Hypsa V, Moran NA. Arsenophonus, an emerging clade of intracellular symbionts with a broad host distribution. BMC Microbiol. 2009; 20(9):143. https://doi.org/10.1186/1471-2180-9-143.

9. Burke GR, Moran NA. Massive genomic decay in Serratia symbiotica, a recently evolved symbiont of aphids. Genom Biol Evol. 2011;3:195-208.

10. Manzano-Marin A, Lamelas A, Moya A, Latorre A. Comparative genomics of Serratia spp.: Two paths towards endosymbiotic life. PLoS One. 2012;7(10).

11. Fenn K, Blaxter M. Are filarial nematode Wolbachia obligate mutualist symbionts? TREE. 2004;19(4):163-6.

12. Ferri $E$, Bain O, Barbuto M, Martin C, Lo N, Uni S, et al. New insights into the evolution of Wolbachia infections in filarial nematodes inferred from a large range of screened species. PLoS One. 2011;6(6):e20843.

13. Nikoh N, Hosokawa T, Moriyama M, Oshima K, Hattori M, Fukatsu T. Evolutionary origin of insect-Wolbachia nutritional mutualism. Proc Natl Acad Sci U S A. 2014;111(28):10257-62.

14. Huigens ME, de Almeida RP, Boons PAH, Luck RF, Stouthamer R. Natural interspecific and intraspecific horizontal transfer of parthenogenesisinducing Wolbachia in Trichogramma wasps. Proc R Soc Lond B. 2004; 271(1538):509-15.

15. Caspi-Fluger A, Inbar M, Mozes-Daube N, Katzir N, Portnoy V, Belausov E, et al. Horizontal transmission of the insect symbiont Rickettsia is plantmediated. Proc R Soc Lond B. 2012;279(1734):1791-6.

16. Dedeine F, Bouletreau M, Vavre F. Wolbachia requirement for oogenesis: occurrence within the genus Asobara (Hymenoptera, Braconidae) and evidence for intraspecific variation in A. tabida. Heredity. 2005;95(5):394-400. 
17. Dedeine F, Vavre F, Shoemaker DD, Bouletreau M. Intra-individual coexistence of a Wolbachia strain required for host oogenesis with two strains inducing cytoplasmic incompatibility in the wasp Asobara tabida. Evolution. 2004;58(10):2167-74

18. Russell JA, Funaro CF, Giraldo YM, Goldman-Huertas B, Suh D, Kronauer DJC, et al. A veritable menagerie of heritable bacteria from ants, butterflies, and beyond: Broad molecular surveys and a systematic review. PLoS One. 2012;7(12):e51027.

19. Weeks AR, Velten $R$, Stouthamer R. Prevalence of a new sex ratio distorting endosymbiotic bacterium among arthropods. Proc R Soc Lond Ser B. 2003; 270:1857-65.

20. Zchori-Fein E, Perlman SJ, Kelly SE, Katzir N, Hunter MS. Characterization of a 'Bacteroidetes' symbiont in Encarsia wasps (Hymenoptera: Aphelinidae): proposal of 'Candidatus Cardinium hertigii'. Int J Syst Evol Microbiol. 2004;54: 961-8.

21. Noel GR, Atibalentja N. 'Candidatus Paenicardinium endonii', an endosymbiont of the plant-parasitic nematode Heterodera glycines (Nemata : Tylenchida), affiliated to the phylum Bacteroidetes. Int J Syst Evol Microbiol. 2006;56:1697-702.

22. Showmaker KC, Walden KKO, Fields CJ, Lambert KN, Hudson ME. Genome sequence of the soybean cyst nematode (Heterodera glycines) endosymbiont "Candidatus Cardinium hertigii" strain cHgTN10. Genome Announc. 2018;6:e00624-18.

23. Chang J, Masters A, Avery A, Werren JH. A divergent Cardinium found in daddy long-legs (Arachnida: Opiliones). J Invertebr Pathol. 2010;105(3):220-7.

24. Nakamura Y, Kawai S, Yukuhiro F, Ito S, Gotoh T, Kisimoto R, et al. Prevalence of Cardinium bacteria in planthoppers and spider mites and taxonomic revision of "Candidatus Cardinium hertigii" based on detection of a new Cardinium group from biting midges. Appl Environ Microbiol. 2009; 75(21):6757-63.

25. Zchori-Fein E, Gottlieb Y, Kelly SE, Brown JK, Wilson JM, Karr TL, et al. A newly discovered bacterium associated with parthenogenesis and a change in host selection behavior in parasitoid wasps. Proc Natl Acad Sci U S A. 2001;98(22):12555-60.

26. Provencher LM, Morse GE, Weeks AR, Normark BB. Parthenogenesis in the Aspidiotus nerii complex (Hemiptera : Diaspididae): a single origin of a worldwide, polyphagous lineage associated with Cardinium bacteria. Ann Entomol Soc Am. 2005;98(5):629-35.

27. Groot TVM, Breeuwer JAJ. Cardinium symbionts induce haploid thelytoky in most clones of three closely related Brevipalpus species. Exp Appl Acarol. 2006;39(3-4):257-71.

28. Gebiola M, White JA, Cass BN, Kozuch A, Harris LR, Kelly SE, et al. Cryptic diversity, reproductive isolation and cytoplasmic incompatibility in a classic biological control success story. Biol J Linn Soc. 2016;117(2):217-30.

29. Gotoh T, Noda H, Ito S. Cardinium symbionts cause cytoplasmic incompatibility in spider mites. Heredity. 2007;98(1):13-20.

30. Hunter MS, Perlman SJ, Kelly SE. A bacterial symbiont in the Bacteroidetes induces cytoplasmic incompatibility in the parasitoid wasp Encarsia pergandiella. Proc R Soc Lond Ser B. 2003;270:2185-90.

31. Perlman SJ, Kelly SE, Zchori-Fein E, Hunter MS. Cytoplasmic incompatibility and multiple symbiont infection in the ash whitefly parasitoid, Encarsia inaron. Biol Control. 2006:39(3):474-80.

32. Nakamura Y, Yukuhiro F, Matsumura M, Noda H. Cytoplasmic incompatibility involving Cardinium and Wolbachia in the white-backed planthopper Sogatella furcifera (Hemiptera: Delphacidae). Appl Entomol Zool. 2012;47(3):273-83.

33. Wu K, Hoy MA. Cardinium is associated with reproductive incompatibility in the predatory mite Metaseiulus occidentalis (Acari: Phytoseiidae). J Invertebr Pathol. 2012;110(3):359-65.

34. Zhang XF, Zhao DX, Hong XY. Cardinium-the leading factor of cytoplasmic incompatibility in the planthopper Sogatella furcifera doubly infected with Wolbachia and Cardinium. Environ Entomol. 2012:41(4):833-40.

35. Nguyen DT, Morrow JL, Spooner-Hart RN, Riegler M. Independent cytoplasmic incompatibility induced by Cardinium and Wolbachia maintains endosymbiont coinfections in haplodiploid thrips populations. Evolution. 2017:71(4):995-1008

36. Takano SI, Tuda M, Takasu K, Furuya N, Imamura Y, Kim S, et al. Unique clade of alphaproteobacterial endosymbionts induces complete cytoplasmic incompatibility in the coconut beetle. Proc Natl Acad Sci U S A. 2017; 114(23):6110-5.

37. Penz T, Schmitz-Esser S, Kelly SE, Cass BN, Muller A, Woyke T, et al. Comparative genomics suggests an independent origin of cytoplasmic incompatibility in Cardinium hertigii. PLoS Genet. 2012;8(10):e1003012.
38. White JA, Kelly SE, Cockburn SN, Perlman SJ, Hunter MS. Endosymbiont costs and benefits in a parasitoid infected with both Wolbachia and Cardinium. Heredity. 2011;106(4):585-91.

39. Penz T, Horn M, Schmitz-Esser S. The genome of the amoeba symbiont "Candidatus Amoebophilus asiaticus" encodes an afp-like prophage possibly used for protein secretion. Virulence. 2010;1 (6):541-5.

40. Santos-Garcia D, Rollat-Farnier PA, Beitia F, Zchori-Fein E, Vavre F, Mouton L, et al. The genome of Cardinium CBtQ1 provides insights into genome reduction, symbiont motility, and its settlement in Bemisia tabaci. Genome Biol Evol. 2014;6(4):1013-30.

41. Showmaker KC, Walden KKO, Fields CJ, Lambert KN, Hudson ME. Genome sequence of the soybean cyst nematode (Heterodera glycines) endosymbiont "Candidatus Cardinium hertigii" Strain CHgTN10. Microbiol Resour Announcements. 2018;6(26)

42. Siozios S, Pilgrim J, Darby AC, Baylis M, Hurst GDD. The draft genome of strain cCpun from biting midges confirms insect Cardinium are not a monophyletic group and reveals a novel gene family expansion in a symbiont. PeerJ. 2019;7.

43. Brown AMV, Wasala SK, Howe DK, Peetz AB, Zasada IA, Denver DR. Comparative genomics of Wolbachia-Cardinium dual endosymbiosis in a plant-parasitic nematode. Front Microbiol. 2018;9.

44. Zeng Z, Fu YT, Guo DY, Wu YX, Ajayi OE, Wu QF. Bacterial endosymbiont Cardinium cSfur genome sequence provides insights for understanding the symbiotic relationship in Sogatella furcifera host. BMC Genomics. 2018;19.

45. Glaeser SP, Kampfer P. Multilocus sequence analysis (MLSA) in prokaryotic taxonomy. Syst Appl Microbiol. 2015;38(4):237-45

46. Maddison WP. Gene trees in species trees. Syst Biol. 1997;46(3):523-36.

47. Edlund A, Ek K, Breitholtz M, Gorokhova E. Antibiotic-induced change of bacterial communities associated with the copepod Nitocra spinipes. PLoS One. 2012;7(3).

48. Fang YW, Liu LY, Zhang HL, Jiang DF, Chu D. Competitive ability and fitness differences between two introduced populations of the invasive whitefly Bemisia tabaci Q in China. PLoS One. 2014;9(6).

49. White JA, Kelly SE, Perlman SJ, Hunter MS. Cytoplasmic incompatibility in the parasitic wasp Encarsia inaron: disentangling the roles of Cardinium and Wolbachia symbionts. Heredity. 2009;102(5):483-9.

50. Lewis SE, Rice A, Hurst GDD, Baylis M. First detection of endosymbiotic bacteria in biting midges Culicoides pulicaris and Culicoides punctatus, important Palaearctic vectors of bluetongue virus. Med Vet Entomol. 2014;28(4):453-6.

51. Perlman SJ, Magnus SA, Copley CR. Pervasive associations between Cybaeus spiders and the bacterial symbiont Cardinium. J Invertebr Pathol. 2010; 103(3):150-5.

52. Zchori-Fein E, Perlman SJ. Distribution of the bacterial symbiont Cardinium in arthropods. Mol Ecol. 2004;13(6):2009-16.

53. Jiggins FM, Bentley JK, Majerus MEN, Hurst GDD. Recent changes in phenotype and patterns of host specialization in Wolbachia bacteria. Mol Ecol. 2002:11(8):1275-83.

54. Hoffmann AA, Clancy D, Duncan J. Naturally-occurring Wolbachia infection in Drosophila simulans that does not cause cytoplasmic incompatibility. Heredity. 1996;76:1-8.

55. Bordenstein SR, Bordenstein SR. Eukaryotic association module in phage WO genomes from Wolbachia. Nat Comm. 2016;7.

56. LePage DP, Metcalf JA, Bordenstein SR, On JM, Perlmutter JI, Shropshire JD, et al. Prophage WO genes recapitulate and enhance Wolbachia-induced cytoplasmic incompatibility. Nature. 2017:543(7644):243 +

57. Partridge SR. Analysis of antibiotic resistance regions in gram-negative bacteria. FEMS Microbiol Rev. 2011:35(5):820-55.

58. Stokes HW, Gillings MR. Gene flow, mobile genetic elements and the recruitment of antibiotic resistance genes into gram-negative pathogens. FEMS Microbiol Rev. 2011;35(5):790-819.

59. Gerth M, Gansauge MT, Weigert A, Bleidorn C. Phylogenomic analyses uncover origin and spread of the Wolbachia pandemic. Nature Comm. 2014;5.

60. Maiden MCJ, Bygraves JA, Feil E, Morelli G, Russell JE, Urwin R, et al Multilocus sequence typing: a portable approach to the identification of clones within populations of pathogenic microorganisms. Proc Natl Acad Sci U S A. 1998:95(6):3140-5.

61. Bleidorn C, Gerth M. A critical re-evaluation of multilocus sequence typing (MLST) efforts in Wolbachia. FEMS Microbiol Ecol. 2018;94(1).

62. Arthofer W, Riegler M, Schuler H, Schneider D, Moder K, Miller WJ, et al. Allele Intersection Analysis: A Novel Tool for Multi Locus Sequence Assignment in Multiply Infected Hosts. PLoS One. 2011;6(7). 
63. Schuler H, Arthofer W, Riegler M, Bertheau C, Krumbock S, Koppler K, et al. Multiple Wolbachia infections in Rhagoletis pomonella. Entomol Exp Appl. 2011;139(2):138-44.

64. Shoji S, Walker SE, Fredrick K. Ribosomal translocation: one step closer to the molecular mechanism. ACS Chem Biol. 2009;4(2):93-107.

65. Reece RJ, Maxwell A. DNA Gyrase - structure and function. Crit Rev Biochem Mol Biol. 1991;26(3-4):335-75.

66. Ayala-Castro C, Saini A, Outten FW. Fe-s cluster assembly pathways in bacteria. Microbiol Mol Biol Rev. 2008;72(1):110 +.

67. Fayet O, Ziegelhoffer T, Georgopoulos C. The GroES and GroEL heat shock gene products of Escherichia coli are essential for bacterial growth at all temperatures. J Bacteriol. 1989;171(3):1379-85.

68. Koressaar T, Remm M. Enhancements and modifications of primer design program Primer3. Bioinformatics. 2007;23(10):1289-91.

69. Untergasser A, Cutcutache I, Koressaar T, Ye J, Faircloth BC, Remm M, et al. Primer3-new capabilities and interfaces. Nucleic Acids Res. 2012;40(15).

70. Messing J. New M13 vectors for cloning. Methods Enzymol. 1983;101:20-78.

71. Edgar RC. MUSCLE: multiple sequence alignment with high accuracy and high throughput. Nucleic Acids Res. 2004;32(5):1792-7.

72. Posada D. jModelTest: Phylogenetic model averaging. Mol Biol Evol. 2008; 25(7):1253-6.

73. Ronquist F, Huelsenbeck JP. MrBayes 3: Bayesian phylogenetic inference under mixed models. Bioinformatics. 2003;19(12):1572-4.

74. Maddison W, Maddison D. Mesquite: A modular system for evolutionary analysis. Version 3.512018 [Available from: http://www.mesquiteproject.org].

\section{Publisher's Note}

Springer Nature remains neutral with regard to jurisdictional claims in published maps and institutional affiliations.

Ready to submit your research? Choose BMC and benefit from:

- fast, convenient online submission

- thorough peer review by experienced researchers in your field

- rapid publication on acceptance

- support for research data, including large and complex data types

- gold Open Access which fosters wider collaboration and increased citations

- maximum visibility for your research: over $100 \mathrm{M}$ website views per year

At BMC, research is always in progress.

Learn more biomedcentral.com/submissions 